\title{
Disintegrated Comet Trail in Southern Tibet
}

\section{Mahesh U. Patil}

Thane, India

Email: mup124@rediffmail.com

How to cite this paper: Patil, M.U. (2018) Disintegrated Comet Trail in Southern Tibet. Open Journal of Geology, 8, 1102-1112. https://doi.org/10.4236/ojg.2018.812067

Received: October 16, 2018

Accepted: November 23, 2018

Published: November 26, 2018

Copyright (C 2018 by author and Scientific Research Publishing Inc. This work is licensed under the Creative Commons Attribution International License (CC BY 4.0).

http://creativecommons.org/licenses/by/4.0/

\begin{abstract}
In southern Tibet, there is a series of lakes in the region $\left(82^{\circ} 30^{\prime} \mathrm{E}, 29^{\circ} \mathrm{N}\right.$ and $\left.90^{\circ} 30^{\prime} \mathrm{E}, 33^{\circ} \mathrm{N}\right)$. This study indicates that these lakes were formed by the impact of a single disintegrating comet that hit the region. Observation indicates that the lakes are unusually closely aligned and have a steep slope facing circular feature on the eastern side. Fractures and faults connecting these lakes can be observed over entire subject site hinting towards the multiple impact craters. The terrain is uneven and lakes are partially filled hence in some cases do not look like circular or elliptical. These lakes vary from $1 \mathrm{Km}$ to $65 \mathrm{Km}$ in diameter and are linearly aligned around a single line. Studies of deuterium by Yuan et al. (2011) [1] indicate an abrupt $4 \%$ increase in $\delta^{18} \mathrm{O}$ in middle Holocene period around 6000 years ago. The study indicates that the region is rich in diamond, Coesite, Platinum Group Elements (PGE), Stishovite, tektites, and other complex alloys, as would be expected from a high energy impact of an extraterrestrial object. The possibility of the impact as one of the reasons for the diamond in this region was also suggested by Wen-Ji Bai and Qing-Song Fang (2007) [2]. However in absence of definitive evidence they favoured mantle origin. Two possible reasons of absence of impact signature are source of sample and impact pattern. First is the source of the sample which is collected from the river beds of Yarlung-Zangbo Suture Zone of Tibet which is believed to be the origin of this diamond, however it ignores the fact that these rivers get water from lakes which are in the proposed impact zone and the second reason is the impact-pattern spread over close to $800 \mathrm{~km}$ which is not expected from the asteroid impact. It will therefore be prudent to test samples from the lake region to understand surface distortion features to confirm the impact. Based on satellite imagery major industrial development supported by road infrastructure in the subject region near lakes and rivers originating from these lakes can be observed hinting towards placer mining activity associated with lakes (craters). Our study suggests that the diamonds, Platinum Group Elements, Stishovite and other alloys harvested from the region should be considered as comet impact diamonds rather than those created in the interior of the earth.
\end{abstract}




\section{Keywords}

Comet Impact, Micro Diamond, Tibet lake, Tektites, Qingsongite, Craters

\section{Introduction}

Tibet has several types of lakes some of them are freshwater whereas others are saline or saltwater lakes. For formation of these lakes multiple theories like the plate tectonics and glacial activity are proposed. However it's a complex network and cannot be justified under a single mechanism. In this study, we propose that most of the lakes between the latitudes of $82^{\circ} 30^{\prime} \mathrm{E}$ and $90^{\circ} 30^{\prime} \mathrm{E}$ longitudes $29^{\circ} \mathrm{N}$ and $33^{\circ} \mathrm{N}$ are formed by a comet impact. The studies conducted by Fang et al. (2007) of The Institute of Geology, Beijing-China [2] and Dobrzhinetskaya et al. (2006) of The University of California on micro-diamond, coesite [3] and other Ultrahigh-Pressure (UHP) minerals have suggested the possibility of impact in the region.

Meteorites, asteroids and comets have collided with the earth in the past, many leaving their imprint in the form of craters. Comet impact craters are different from asteroids because of their size, velocity, strength and density. Comet Nuclei range from a few hundred meters to tens of kilometers across and are composed of loose collections of ice, dust, and small rocky particles, The Comets are distinguished from asteroids by the presence of an "extended, gravitationally unbound atmosphere" surrounding their central nucleus as a result comet has different entry and impact pattern. On one hand its composition makes it very fragile body which will break easily under influence of gravitational and frictional force, however since it has its own atmosphere it will act as cushion while making entry into the earth's atmosphere and will substantially reduce the friction, avoiding vaporization in the path allowing most of the material to fall on the earth. Hence comet impact will scatter over a large area. On the surface of the earth 190 impact craters have been recognised as listed in the "database of the Planetary and Space Science Centre University of New Brunswick, Canada" [4]. They are typically marked by a raised rim and central hills in the middle of large craters. Many more impact craters are expected to have been obliterated over the geological history because of multiple factors, such as tectonics, weathering, volcanic activity etc. on the earth.

The impact of small bodies is controlled by our atmosphere which acts as a shield and vaporizes them before they can touch the ground. For larger bodies, the crater depends on their composition and fragmentation in the atmosphere.

\subsection{Comet and Impact Patterns}

Examples like those of Comet Shoemaker Levy 9 [5] show that it is not unusual for comets to break up into multiple pieces due to gravitational gradients around a large planet. Earth, because it's a small planet, such gravitational gradients are 
small, probably not enough to break comet, like shoemaker broke in to 21 pieces but due to radiation effects in terrestrial planet region comet will become fragile enough to break under Earth's gravitational gradient hence collision of such nature would, therefore, create a series of impressions on the ground. Then there are tektites, small, glassy aerodynamical dusty earth material, which is thrown outward from the earth as ejecta by an impact and re arrive on earth after travelling through the atmosphere on their ballistic trajectory. The study of comet impact of Sahara desert show desert glass spread over $6000 \mathrm{sq.km}$. is possible because of similar entry and impact pattern. The study indicates that the series of lakes seen in southern Tibet were caused by the impact of one such disintegrating comet.

This Impact pattern to be known as Shoemaker-Vyas Pattern (SVP) in the respect of visionary personalities (Figure 1).

Based on the SVP impact patterns and other findings like tektites, micro diamonds, series of lakes/dry lakes in sites like Egypt, South Australia Glikson A. (2013) [6] and few other possible comet impact sites can be studied.

\subsection{Other Possible Comet Impact Site under Study and Features as per Proposed Pattern}

Sahara comet collision and Diamond-Andrew Fazeka (Oct 2013)-National Geographic [7].

The Sahara Desert, Comet Impact is under study as per current theory comet busted in mid-air over this region, however, features on the ground are similar to proposed impact pattern (SVP) and can be observed over approximately 900 $\mathrm{km}$ of the proposed impact zone. Each of the proposed circular features is approximately $25 \mathrm{~km}$ in diameter (Figure 2). Since it's a desert area many such features will be covered by sand.

Unique Chemistry Of Diamond Bearing Pebble From The Libyan Desert Glass Strewnfield, SW Egypt: Evidence For Shocked Comet Fragment, this glass is spread over a large area of Sahara close to 6000 sq.km., Chemical Analysis confirm the origin from the comet nucleus, It was created as a result of heated sand at $2000^{\circ} \mathrm{C}$.

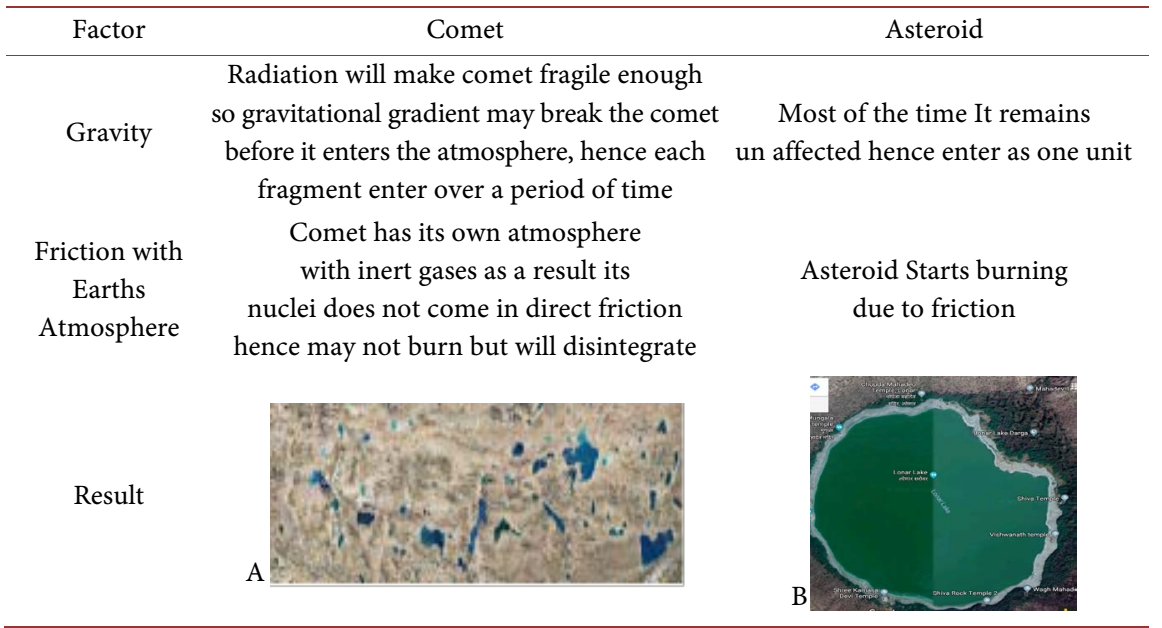

Figure 1. (SVP) A: Comet Impact pattern B: Asteroid pattern. 




Figure 2. A possible Sahara impact pattern B, C, D: Possible crater like features.

\section{Data on Proposed Tibet Impact}

2.1) lake Features and Circumstantial evidence 2.2) Diamond and Coesite bearing chromitites 2.3) Minerals and alloys 2.4) Tektite.

\subsection{Lakes Features}

We identify a region between $82^{\circ} 30^{\prime} \mathrm{E}$ and $90^{\circ} 30^{\prime} \mathrm{E}$ and $29^{\circ} \mathrm{N}$ and $33^{\circ} \mathrm{N}$ in southern Tibet (Figure 3). The top panel shows the region of Tibet studied here. The second panel shows the lake region marked in Figure 3A. The third panel shows the marking of each lake in the region. As can be seen from the figure, the craters seem to be roughly aligned. In Table 1 below we give the property of the lakes.

\subsubsection{Lake Characteristics (Based on Google Map Images)}

1) Most of them have a circular/oval shape on one side.

2) These lakes are formed in a straight line creating the resemblance of geometric time impact.

3) These Lakes have 2 - 90 meter of depth.

4) Steep Slope facing circular feature.

5) Water on Eastern Side Is having deep blue/green shade indicating more depth than western side.

6) Small lakes have crater-like appearance (created by angular impact).

7) Large lakes appear to be a combination of two or three water bodies/craters.

8) Fractures and fault lines interconnecting these lakes hinting towards impact that cracked the whole surface.

9) “D” levels of water show anomalies (Though they are attributed to evaporative enrichment) that need to be studied in fresh perspective.

10)Lake Karakul (Known Impact Crater) is a key reference because of its sedimentary rock similar to subject site. Though it is not a part of the subject site 
it has similar geographical conditions and is similar to lakes in Tibet.

11)Tektites reported from placer deposits and dry lake beds.

12)Tektites found in Vietnam, Laos and other parts of Mekong Delta (possibly originating from Tibet) strongly indicate a new strewn for its origin.

\subsubsection{Age of the Lakes}

Study on the evaporative enrichment of oxygen 18 published by Fasong Yuan et al. (2011) [1], indicate that there is an abrupt $4 \%$ increase in $\delta^{18} \mathrm{O}$ in middle Holocene at approximately 6000 years BP. This indicates towards major change in the lake composition because of external factor. Comet has D-excess water and can be responsible for such fluctuation. Current study of Yuan et al. (2011) [1] focus on evaporative enrichment hence this water should be studied in a fresh perspective.

Table 1 . The property of the lakes.

\begin{tabular}{|c|c|c|c|c|c|c|c|c|}
\hline Lake Name & Location & $\mathrm{L}(\mathrm{KM})$ & $\mathrm{B}(\mathrm{KM})$ & $\delta \mathrm{D} \%$ & $\delta^{18} \mathrm{O} \%$ & $\mathrm{~d} \% \mathrm{o}$ & Key Features & Appearance \\
\hline Dagze Co. & $31.8,87.5$ & 25 & 17 & -69.50 & -6.38 & -18.4 & $\begin{array}{l}\text { Circular Edge On } \\
\text { Eastern Side }\end{array}$ & Oval Crater \\
\hline Garen Co & $30.7,84.9$ & 13 & 5.3 & -152 & -19.85 & 6 & $\begin{array}{l}\text { Circular Edge On } \\
\text { Eastern Side }\end{array}$ & $\begin{array}{c}\text { Oval Crater with } \\
\text { extended water bodies }\end{array}$ \\
\hline Rinquin Xubco & $31.3,83.4$ & 21 & 15.3 & -64 & -5.70 & -19.1 & $\begin{array}{l}\text { Circular Edge On } \\
\text { Eastern Side }\end{array}$ & Oval Crater \\
\hline Zige Tangco & $32.0,90.9$ & 20 & 18 & -68 & -6.07 & -19.5 & $\begin{array}{l}\text { Circular Edge On } \\
\text { Eastern Side }\end{array}$ & Oval Crater \\
\hline Kyebxang Co & $32.4,89.9$ & 20 & 13 & NA & NA & NA & $\begin{array}{c}\text { Circular Edge On } \\
\text { Eastern Side }\end{array}$ & $\begin{array}{l}\text { Oval Crater } \\
\text { with extended } \\
\text { water bodies }\end{array}$ \\
\hline Zhari Namco & $30.9,85.6$ & 54 & 24 & -75 & -6.67 & -21.8 & $\begin{array}{l}\text { Circular Edge on } \\
\text { North East side }\end{array}$ & $\begin{array}{l}\text { Elongated body, } \\
\text { looks like multiple } \\
\text { impact crater }\end{array}$ \\
\hline Dibu co & $30.7,84.8$ & 12 & 7 & -66 & -4.37 & -30.6 & $\begin{array}{l}\text { Circular Edge on } \\
\text { East side }\end{array}$ & $\begin{array}{c}\text { Oval Crater } \\
\text { with extended } \\
\text { water bodies }\end{array}$ \\
\hline Daru co & $31.7,90.7$ & 19 & 4 & -70 & -6.40 & -18.4 & $\begin{array}{l}\text { Circular Edge on } \\
\text { East side }\end{array}$ & $\begin{array}{c}\text { Oval Crater } \\
\text { with extended } \\
\text { water body }\end{array}$ \\
\hline Dawa Co & $31.2,84.9$ & 14 & 9.36 & -75 & -6.87 & -20.9 & $\begin{array}{c}\text { Circular Edge on } \\
\text { East side }\end{array}$ & Oval Crater \\
\hline Baingoin & $30.9,89.9$ & 8 & 6 & NA & NA & NA & $\begin{array}{c}\text { Circular Edge on } \\
\text { East side }\end{array}$ & Oval Shape \\
\hline
\end{tabular}

Lake Table and Data (Yuan, 2011) [1]. 


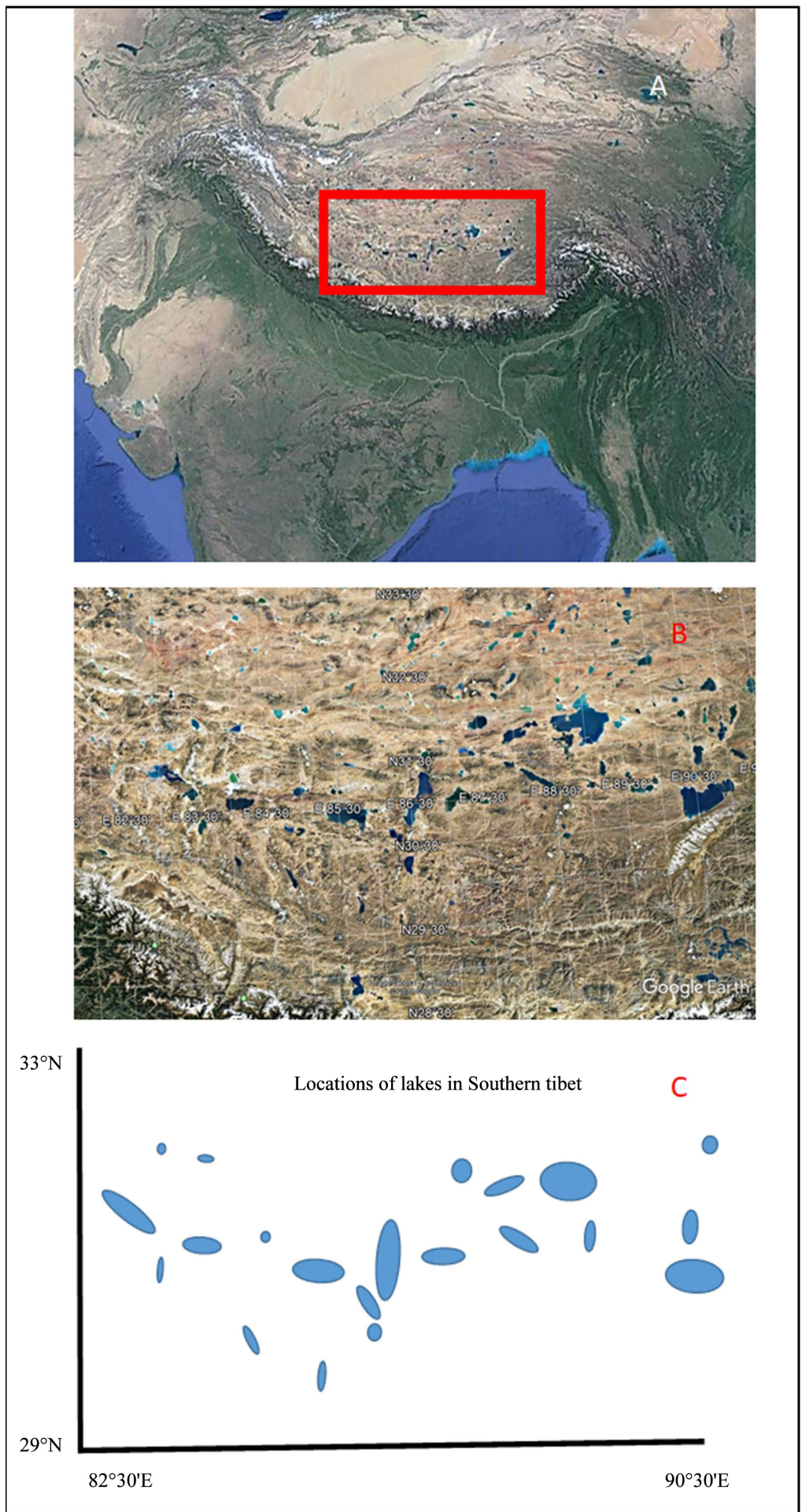

Figure 3. A: Region of Tibet; B: Lake region; C: Marking of each lake.

\subsubsection{Circumstantial Evidence in the Subject Site (Based on Google Map Images)}

Industrial units near the origin of rivers starting from these lakes indicate alluvial/Placer mining activity (Figure 4). More than 30 such units near lakes can be seen on the satellite map (Google Map) with connecting road network (S205, 
$301,302)$. This is a remote and inhabitable region thus operating such heavy industry supported by infrastructure indicate towards the large commercial interest in the lake region, hence lake region is the possible source of micro-diamond, coesite, and other commercially important minerals. It will be prudent to collect the sample from this region to verify UHP impact instead of Yarlung-Zangbo Suture Zone (Figure 5).

Sample collection zone (Yarlung Zangbo Region) approximately $200 \mathrm{~km}$ away from the proposed craters possible reason of non-evidence of Impact.

\subsection{Diamond and Coesite Bearing Chromitites from the Luobusaophiolite}

Fang (2007) [2] discusses diamonds and ultrahigh pressure minerals found in Tibet are incorporated in the chromitites in the deep upper mantle or they are result of impact but since there is "absence of evidence" of impact, study is indicating its origin from earth's mantle this is in sharp contrast with Sahara Diamond case since even in Sahara no impact crater has been identified for Comet impact but detailed investigation of Diamond is carried out to prove its origin.

\subsubsection{Sample Analysis}

Fang et al. (2007) [2] and Yang. J, Larissa Dobrzhinetskaya et al. (2006) [3] indicate towards the possibility of impact origin.

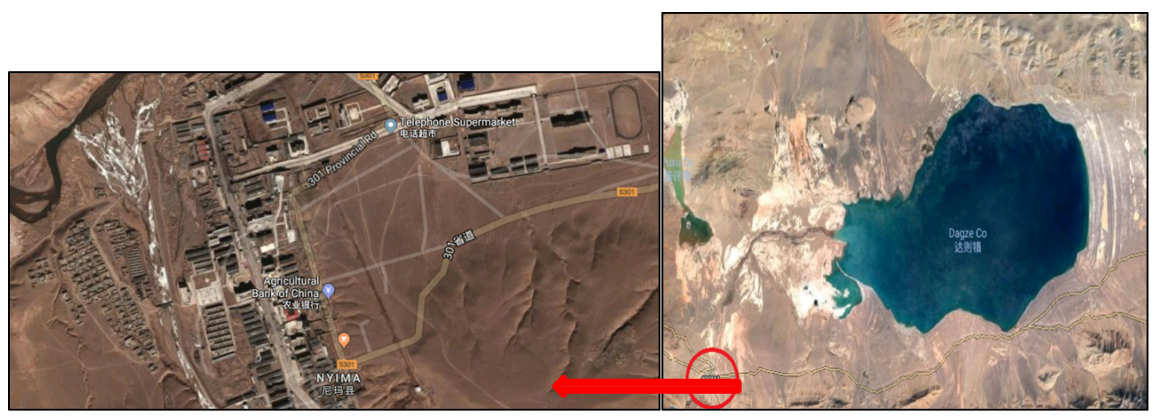

(a)

(b)

Figure 4. (a) Industrial/mining activity on River; (b) Lake Dagze Co.

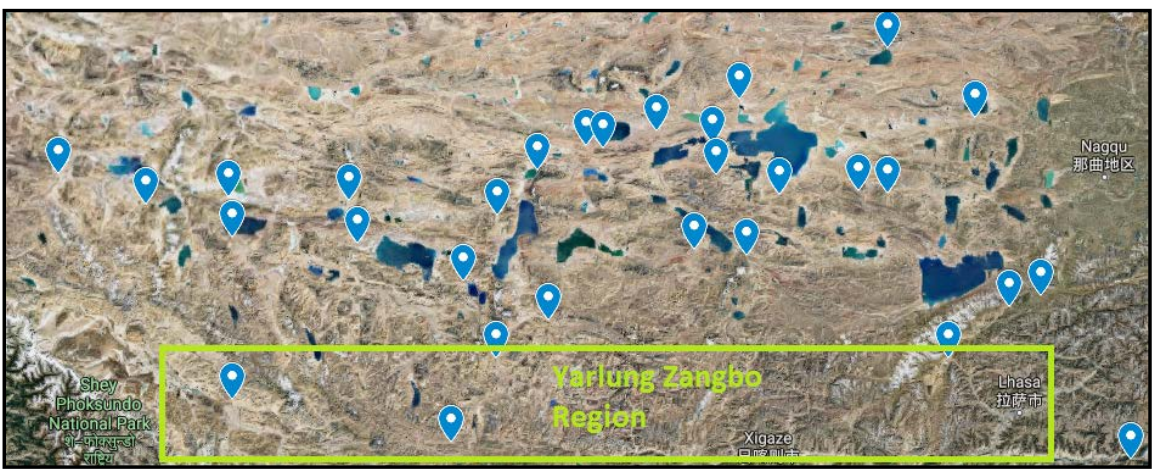

Figure 5. Blue Flag: Industry/Placer mine; Green Box: Sample collection zone of earlier Studies. 
1) Association of Diamond and Coesite is surprise find, it occurs mainly in UHP metamorphic rock in meteorite impact craters.

2) These diamonds UHP minerals in Luobusa chromitites can originate either from deep earth source or meteorite impact. However, these minerals have a shallow origin. Only in absence of evidence of meteorite impact study is concluding that it has the origin in deep upper mantle. This need to be reviewed.

3) Presence of PGE is again characteristic of impact.

4) The Unique case of kyanite along with $\mathrm{Ti}$ and Osbornite (TiN) must be seen in co-relation with NASA study of comet dust "Comet 81 p/Wild2" [8] which confirms the presence of $\mathrm{Ti}$ in comet.

\subsubsection{Raman Peak}

Kyanite: Study of Dr. Fang [2] the apparently amorphous phase with variable composition yielded no Raman peaks in the entire spectrum from 140 to 4000 $\mathrm{cm}^{-1}$. Its composition does not match any known mineral or natural melt.

\subsection{Minerals and Alloys}

1) Ti-rich Kyanite is a unique finding in Tibetan region Mr. Fang's [2] study reveals that $\mathrm{Ti}$ presence in kyanite varies from (1.98 - $11.64 \mathrm{wt} \%$ ). Analysis of dust of comet 81/P wild 2 [8] confirms the presence of $\mathrm{Ti}$ in the comet. Hence Kyanite association with Ti must be reviewed from the impact perspective.

2) Osbornite (TiN): Laser-Raman spectroscopic and XPS Study conducted by Prof. G. Parthasarthy [9] also strongly recommend extraterrestrial origin.

3) Qinsongite and its origin (BN): In 2013 International Mineralogical Association Recognized it as only known boron mineral formed in deep earth mantle found in Luobusha ophiolite, Tibet autonomous Region in China. Boron is rare in the universe, it is formed in minor amounts in cosmic ray spallation and may be found in cosmic dust or meteoroid. Boron is a rare element in earth crust $(0.001 \%)$ however it can be highly concentrated by the action of water thus it is found in compounds such as borax, boric acid. Tibet lake region is one of the main sources of borax on earth. Thus if it is undergoing any transformation due to any reason to form a new mineral then natural source is available on the surface itself. If we look at the associated minerals that are found with "Qingsongite" then all these minerals require different conditions in the deep earth mantle. Elements like Os, Ir, micro diamond, Kyanite with $\mathrm{Ti}$, Coesite finding in association with qingsongite indicate that they have undergone the transformation under the uniform condition on the surface itself thus they coexist in one crystal. Its hardness on the Mohs scale is $9-10$ which also indicate towards UHP impact in its formation. All these minerals are found in placer deposits which again indicate towards the shallow origin.

4) Platinum group elements in the sample are characteristics of Impact. 
Mr. Xu-Feng [10] Study also Indicate the Presence of Following Alloys

- In Cr-c alloy $\mathrm{Cr}$ is not native.

- Fractured shiny grains of Fe-Si alloy are found which he is trying to co-relate with findings in other parts of the world which are formed by the impact of lightning (but to our knowledge Tibet is not known for such heavy lightning) so the source of impact need review.

- Many complex alloys and minerals that are detected are similar to minerals found near impact sites e.g. Zircon, Garnet.

- Formation of so many alloys itself create doubt about the formation process.

\subsection{Tektites}

Tektites have been reported from placer deposits and dry lake beds (unconfirmed sources) are a strong evidence of impact.

Neighborhood Occurrence: Vietnam, Laos, Cambodia and in some cases found in Thailand and China (Indochinites).

As on date, it is believed that Indochinites are of Australian Strewn field, however, no impact crater has been identified. Australian Tektites are concentrated in southern Australia hence neither plate tectonics, nor ocean current can explain their presence in mainland of places like Laos, Vietnam. The main source of this spread is the Mekong which originates from Tibet. Hence these Tektites are from Independent strewn possibly from Tibet (Figure 6).

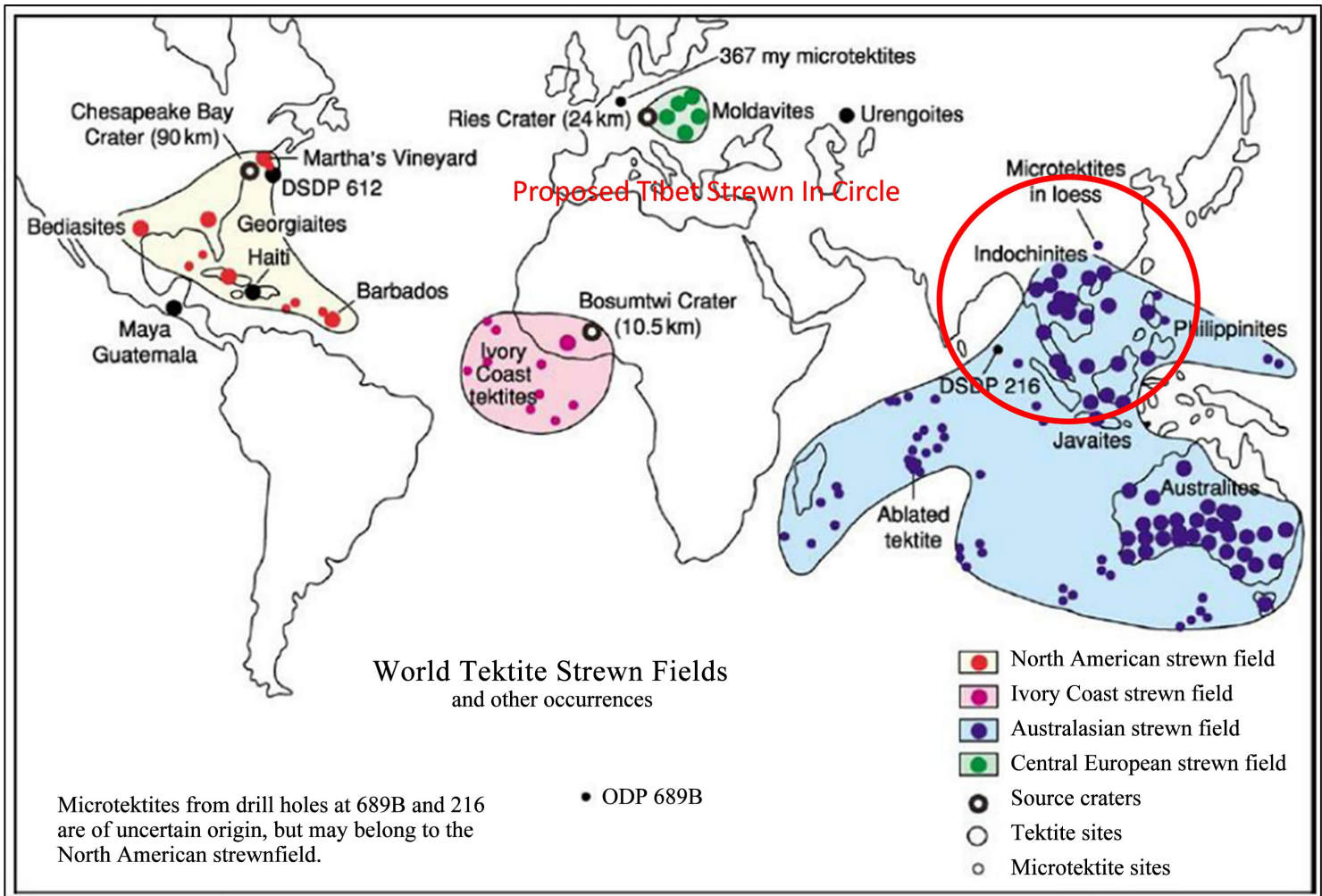

Figure 6. Red Circle Indochinites and Tibetites possible independent strewn from Australian strewn. Source: Known Tektite Strewn Fields and Finds from McCall (2005) [11] D11. 


\section{Sample Collection and Its Limitations to Impact Theory}

Mr. Xu-Feng [10] has reported sample from 2913.86N, 9211.32E and Prof. Fang Qing-Song in his report also mentioned sample collection from Yarlung-Zangbo Suture Zone of Tibet.

This location is $200-300 \mathrm{Km}$ away from proposed impact zone and is on the river bank (the river is originating from the proposed zone) Hence diamonds can be found in the river bed but finding impact evidence at such distances is difficult. To get the correct perspective on the origin of diamond it is prudent to test sample from the origin of the river rather than searching it in sediments of the river. Samples should be collected from lakes like Dagze co to obtain complete clarity about its origin.

\section{Conclusions}

On the basis of Diamonds, PGE and other alloys found in Tibet with ambiguity about its origin, Ti-rich Kyanite, Tektites, proximity of lakes and their shapes with crater-like features, D level data and Oxygen 18 study data indicating origin/fluctuation at close to 6000 years, we would like to propose that disintegrated comet has collided in the Tibetan region between the latitudes of $82^{\circ} 30^{\prime} \mathrm{E}$ and $90^{\circ} 30^{\prime} \mathrm{E}$ and $29^{\circ} \mathrm{N}$ and $33^{\circ} \mathrm{N}$ approximately 6000 years back forming series of large impact craters. A fresh study of the sample from the proposed region will help to obtain better clarity.

This study has taken reference and inspiration from story of ancient literature which talks about similar event in the region.

\section{Acknowledgements}

We wish to thank Prof. Narendra Bhandari and Prof. Jayant Naralikar for useful discussions and guidance.

We thank

- Dr.Anil Bhardwaj-Director PRL and Mrs.Pauline-PRL.

- Dr.G.Parthasarthy-Chief Scientist-NGRI.

- Prof.Ranganath Navalgund-ISRO.

- Prof.M.S.Sisodia.

- Prof.Kanchan Pande-IIT Mumbai.

- Prof. Wickramsinghe.

- Prof.Ranjan Gupta-Iucca.

- Prof.Diwakar and Prof P. Sreekumar-Scientific Secretary, ISRO.

- Google Scholar and Google search engine.

This paper is prepared under a able guidance of a very good person from scientific community however person has decided to stay away from the subject because of certain points about which person is sensitive.

\section{Conflicts of Interest}

The author declares no conflicts of interest regarding the publication of this paper. 


\section{References}

[1] Yuan, F., et al. (2011) Study of Evaporative Enrichment of Oxygen 18 and Deuterium Level in Tibetan Lakes. Journal of Paleolimnology, 46, 291-307. https://doi.org/10.1007/s10933-011-9540-y

[2] Fang, Q.-S., et al. (2007) Diamond Andcoesite Bearing Chromitites from the Luobusaophiolite. Tibet Geology, 35, 875-878. https://doi.org/10.1130/G23766A.1

[3] Dobrzhinetskaya, L., et al. (2006) Diamond and Coesite after Former Stishovite in Tibet Ophiolite. American Geophysical Union, Fall Meeting 2006, Abstract id.V44B-01.

[4] http://www.passc.net/EarthImpactDatabase/index.html

[5] Shoemaker, C.S., et al. (1993) Comet Shoemaker-Levy (1993e) IAU Circ. No. 5725, $\# 1$.

[6] Glikson, A. (2013) Evidence for Twin Asteroid Mega-Impacts, Warburton Basin N.E.S. Australia. MESA Journal, 69, 36-41.

[7] Fazeka, A. (2013) National Geographic.

[8] Flynn, G.J. (2007) Comet 81p/Wild 2 Study by NASA. Journal Earth, Moon, and Planets, 102, 1-4.

[9] Parthasarthy, G. (2016) Osbornite Study by Dr. G. Parthasarthy-CSIR-NGRI, Hyderabad Paper No 1486.

[10] Xu, F. (1999) Diamond Analysis Study Report.

[11] McCall (2005) Known Tektite Strewn Fields and Finds from McCall.

\section{Appendix}

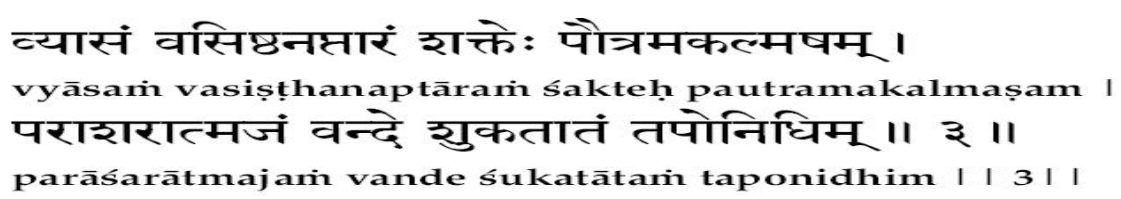

\section{Meaning}

Sage Vyasa is the great-grandson of Sage Vasishta and the grand-son of Sakti. He is the son of Paraasara and the father of Suka. I offer my obeisance to that Sage Vyasa who is free from all defects and is a treasure of penance (Tapas). 